\title{
Short-Term Effects of Tumor Necrosis Factor on Energy and Substrate Metabolism in Dogs
}

\author{
Yoichi Sakurai, Xiao-jun Zhang, and Robert R. Wolfe \\ The Metabolism Unit, Shriners Burns Institute, and Departments of Surgery and Anesthesiology, \\ The University of Texas Medical Branch, Galveston, Texas 77555-1220
}

\begin{abstract}
In vivo short-term effects of recombinant human TNF- $\alpha$ on lipolysis, FFA flux, fat oxidation, triglyceride-fatty acid cycling, and glucose kinetics were evaluated with stable isotopic tracers and indirect calorimetry along with monitoring of hemodynamic parameters in fasted dogs. High-dose TNF infusion $(10 \mu \mathrm{g} / \mathrm{kg})$ caused a fall in mean arterial pressure $(P<0.01)$, pulmonary arterial pressure $(P<0.001)$, and cardiac index (CI) $(P<0.05)$. The rate of appearance of glycerol ( Ra glycerol) and the rate of appearance of FFA (Ra FFA) were decreased by $20 \%(P<0.05)$ and by $42 \%(P<0.01)$, respectively. Total fat oxidation fell by $23 \%(P<0.05)$. In contrast, TNF infusion significantly increased glucose production by $13 \%(P<0.05)$ and metabolic clearance rate of glucose by $25 \%$ $(P<0.01)$. However, TNF infusion did not change energy expenditure. Low-dose TNF infusion $(3.5 \mu \mathrm{g} / \mathrm{kg})$ caused changes similar in all respects, except magnitude, to the highdose effects. There was a significant correlation between percent change of $\mathrm{CI}(\Delta \mathrm{CI})$ and percent change of rate of appearance of palmitate (Ra palmitate; $\Delta$ Ra palmitate $)(P<0.0001, r$ $=0.69)$, Ra FFA $(\triangle \operatorname{Ra} F F A)(P<0.0001, r=0.60)$, and Ra glycerol ( $\triangle$ Ra glycerol $)(P<0.0329, r=0.36)$. The correlation between $\Delta \mathrm{CI}$ and $\Delta \mathrm{Ra}$ palmitate was greater than the correlation between $\Delta C I$ and $\Delta R a$ glycerol $(P=0.028)$. We conclude that the acute response to TNF causes a shift towards carbohydrate as an energy substrate in a dose-dependent manner by both decreasing the availability of FFAs and increasing glucose production. (J. Clin. Invest. 1993.91:2437-2445.) Key words: stable isotopes • lipolysis • fatty acid flux • reesterification • tumor necrosis factor
\end{abstract}

\section{Introduction}

In clinical situations such as trauma, sepsis, and cancer, marked changes in glucose $(1,2)$ and lipid $(3,4)$ metabolism occur that may affect both morbidity and mortality (5). Alterations in lipid kinetics that ultimately lead to hepatic fat accumulation, thereby possibly contributing to metabolic failure of the liver $(6,7)$, have been of particular concern. Many studies

Address correspondence and reprint requests to Robert W. Wolfe, Ph.D., Shriners Burns Institute, 815 Market Street, Galveston, TX 77555-1220.

Portions of this work have appeared in abstract form (1992). FASEB (Fed. Am. Soc. Exp. Biol.) J. 6:a1088.

Received for publication 28 April 1992 and in revised form 28 December 1993.

J. Clin. Invest.

(c) The American Society for Clinical Investigation, Inc. 0021-9738/93/06/2437/09 \$2.00

Volume 91, June 1993, 2437-2445 have attempted to elucidate control mechanisms responsible for altered substrate kinetics in critically ill patients (8). In this regard, considerable interest has recently centered on the metabolic effects of TNF, which is a polypeptide produced by lymphocytes or macrophages as part of the inflammatory reaction to stress, infection, or malignancy $(9,10)$. TNF was originally identified by its ability to cause hemorrhagic necrosis in certain transplanted tumors (11) and was subsequently shown to have cytotoxic and cytostatic effects on many transformed cells in culture (12). TNF can be highly toxic and was shown to be an important primary mediator of certain responses in endotoxininduced shock $(13,14)$. Furthermore, TNF was shown to decrease lipoprotein lipase (LPL) activity in the 3T3-L1 cell system (15), which could be anticipated to cause an elevation in plasma triglyceride concentration if it occurred in vivo. However, more recent data have failed to confirm an effect on LPL in vitro (16). Another in vitro study showed that TNF decreased the synthesis and storage of lipid (17). Although there is a report in which administration of TNF produced a hypermetabolic response, with increased glycerol and free fatty acid turnover seen in some (but not all) patients with disseminated cancer (18), the precise effects of TNF on lipid kinetics still remained to be established.

Other aspects of the effect of TNF on lipid metabolism are similarly uncertain, with conflicting reports regarding its effect on adipocyte metabolism (17) and lipogenesis (19). A detailed evaluation of the effects of TNF on fatty acid metabolism has yet to be performed. Such an analysis should include quantification of the triglyceride-fatty acid (TG-FA) cycle (20). In this cycle, fatty acids released during the process of lipolysis are subsequently reesterified rather than oxidized. Reesterification can occur within the adipocyte (intraadipocyte recycling), or the fatty acid can be released and reesterified in the liver (extraadipocyte recycling). Since most fatty acids incorporated into hepatic triglyceride come from peripheral lipolysis, an elevated rate of extraadipocyte TG-FA recycling could lead to hepatic fatty deposition if the mechanism for TG secretion were defective. TG-FA cycling is under both hormonal (21) and substrate (22) control. It has been shown to be elevated in numerous pathological conditions $(20,23)$ and therefore appears to play a central role in the development of fatty livers in critically ill patients.

The present study was performed to determine the effect of recombinant human TNF- $\alpha$ on lipolysis, free fatty acid flux, fat oxidation, TG-FA cycling, glucose kinetics, and energy expenditure, using anesthetized dogs. Stable isotopes were used to

1. Abbreviations used in this paper: $\mathrm{CI}$, cardiac index; GCMS, gas chromatography-mass spectrometry; LPL, lipoprotein lipase; MCR, metabolic clearance rate; $\mathrm{m} / \mathrm{e}$, mass/charge ratio; $\mathrm{Ra}$, rate of appearance; TG-FA, triglyceride-fatty acid; TPRI, total peripheral resistance index. 
determine lipid and glucose kinetics by measuring the rate of appearance $(\mathrm{Ra})$ of glycerol, palmitic acid, and glucose in blood plasma and indirect calorimetry was used to measure energy metabolism.

\section{Methods}

Animals and experimental protocol. This study was approved by the Animal Welfare Committee of The University of Texas Medical Branch. Dogs were obtained $\geq 1 \mathrm{wk}$ before study and were housed in the Animal Resource Center of The University of Texas Medical Branch in accordance with the guidelines of the Committee on Care and Use of Laboratory Animals of the Institute for Laboratory Animal Resources, the National Research Council. The animals were fed with a commercially available dog chow (Lab Canine Diet no. 5006; Purina Molls, Inc., Richmond, IN). On the morning after an overnight fast of $16 \mathrm{~h}$ the animals were anesthetized with pentobarbital sodium $(30 \mathrm{mg}$ / $\mathrm{kg}$ body wt; Abbott Laboratories, North Chicago, IL) and endotracheal intubation was performed. The dogs spontaneously breathed room air. After catheterization of the urinary bladder, the operative areas were shaved and cleansed with povidone-iodine. With aseptic technique a Teflon catheter (Intramedicut Catheter Kit; Sherwood Medical Industries Inc., St. Louis, MO) was placed in the common carotid artery for arterial sampling and pressure monitoring. Another catheter was placed in the ipsilateral external jugular vein for the infusion of isotopes, saline, and TNF. A Swan-Ganz thermodilution catheter (model 93-132-5F; American Edwards Laboratories, Irvine, CA) was placed into the pulmonary artery through the contralateral external jugular vein. Supplementary doses of anesthetic agent were given as required to maintain light general anesthesia throughout the experiment. Cardiac output was measured with the Swan-Ganz catheter and a cardiac output computer (model 9520A; American Edwards, Palo Alto, CA). The cardiac index was determined from the equation: body surface area $=0.118 \times$ body $\mathrm{wt}(\mathrm{kg})^{2 / 3}$. Total peripheral resistance index (TPRI) was determined by dividing the mean arterial pressure by the cardiac index (the results are reported as dyn $\cdot \mathrm{s} \cdot \mathrm{cm}^{-5} \cdot \mathrm{m}^{-2}$ ) $(24)$. All of these hemodynamic parameters were monitored every $20 \mathrm{~min}$ throughout the experiment.

The experimental protocol is illustrated in Fig. 1. Oxygen consumption and carbon dioxide production were measured by indirect calorimetry using a metabolic cart (Horizon; SensorMedics Corp., Anaheim, CA), from which energy expenditure was calculated. After baseline blood samples were collected, a primed $(17.6 \mu \mathrm{mol} / \mathrm{kg})$ constant $\left(0.22 \mu \mathrm{mol} \cdot \mathrm{kg}^{-1} \cdot \mathrm{min}^{-1}\right)$ infusion of $\left[6,6-\mathrm{d}_{2}\right]$ glucose $(98.5 \%$ enriched; Tracer Technologies Inc., Somerville, MA) and [2$d_{1}$ ] glucose ( $98 \%$ enriched; MSD Isotopes, Montreal, Quebec, Canada) was started and maintained for 240 min using a calibrated syringe pump (Harvard Apparatus, South Natick, MA). The exact infusion rate in each experiment was determined by measuring glucose concentration in the infusate. At $30 \mathrm{~min}$, a primed $(1.5 \mu \mathrm{mol} / \mathrm{kg})$ constant $\left(0.1 \mu \mathrm{mol} \cdot \mathrm{kg}^{-1} \cdot \mathrm{min}^{-1}\right)$ infusion of $\left[{ }^{2} \mathrm{H}_{5}\right]$ glycerol $(98.2 \%$ enriched; MSD Isotopes) dissolved in $0.9 \% \mathrm{NaCl}$ and a constant $(0.04$ $\left.\mu \mathrm{mol} \cdot \mathrm{kg}^{-1} \cdot \mathrm{min}^{-1}\right)$ infusion of $\left[1-^{13} \mathrm{C}\right]$ palmitic acid $(99 \%$ enriched; MSD Isotopes) bound to 5\% albumin (Alpha Therapeutic Corp., Los Angeles, CA ) were started and maintained for $210 \mathrm{~min}$. At $120 \mathrm{~min}$, one of two different doses of primed constant infusion of TNF (kindly supplied by Genentech Inc., South San Francisco, CA) was started and maintained for $120 \mathrm{~min}$. Group 1 (high-dose TNF infusion, $n=8$ ) received $10 \mu \mathrm{g} / \mathrm{kg}$ of TNF administered as a $2.5-\mu \mathrm{g} / \mathrm{kg}$ bolus followed by a $62.5 \mathrm{ng} \cdot \mathrm{kg}^{-1} \cdot \mathrm{min}^{-1}$ continuous infusion. Group 2 (low-dose TNF infusion, $n=6$ ) received $3.5 \mu \mathrm{g} / \mathrm{kg}$ of TNF administered as a 1.5 $\mu \mathrm{g} / \mathrm{kg}$ bolus followed by a $16.7 \mathrm{ng} \cdot \mathrm{kg}^{-1} \cdot \mathrm{min}^{-1}$ continuous infusion. TNF was mixed with $0.9 \%$ saline containing $0.25 \%$ albumin to prevent adhesion of TNF to the container and was infused at a constant rate of $0.25 \mathrm{ml} / \mathrm{min}$. An equal amount of solution without TNF was given to the control animals (group 3 ) in the last $2 \mathrm{~h}(n=5)$. The total volume of saline administered during the study was $15-20 \mathrm{ml} \cdot \mathrm{kg}^{-1} \cdot \mathrm{h}^{-1}$.

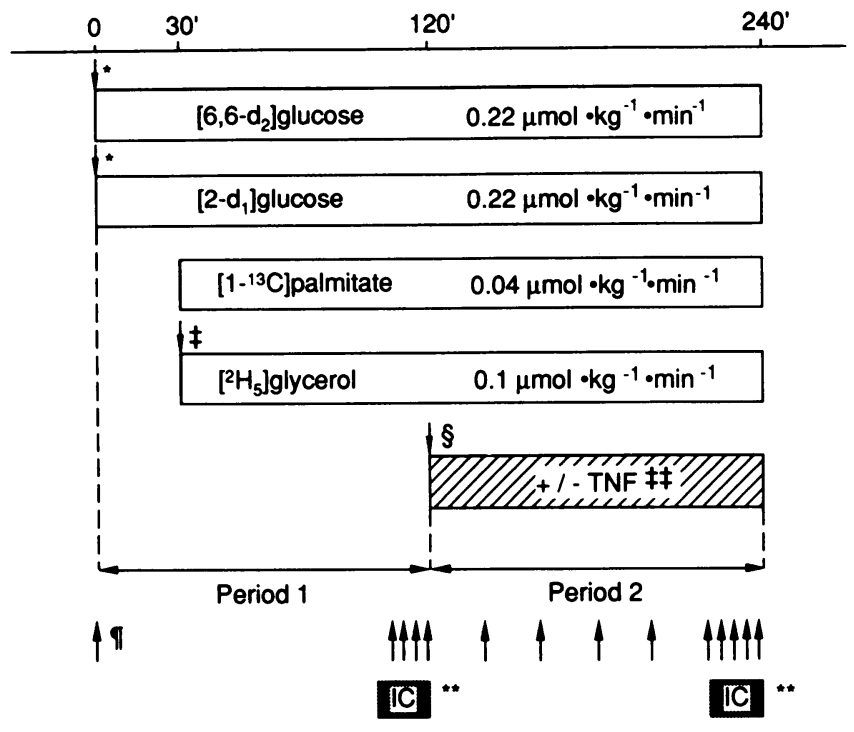

Figure 1. The schematic representation of the experimental protocol. *Priming dose of $\left[6,6-d_{2}\right]$ glucose and [2-d $\left.d_{1}\right]$ glucose at $17.6 \mu \mathrm{mol} / \mathrm{kg}$. ${ }^{\ddagger}$ Priming dose of $\left[{ }^{2} \mathrm{H}_{5}\right]$ glycerol at $1.5 \mu \mathrm{mol} / \mathrm{kg}$. ${ }^{\S}$ Priming dose of TNF at 2.5 and $1.5 \mu \mathrm{g} / \mathrm{kg}$ for high-dose TNF infusion (group 1) and lowdose TNF infusion (group 2), respectively. 'Blood samples were taken for the measurement of enrichments. ${ }^{* *}$ Indirect calorimetry.

${ }^{\ddagger}$ Primed-continuous infusion of TNF in group $1(62.5$ $\left.\mathrm{ng} \cdot \mathrm{kg}^{-1} \cdot \mathrm{min}^{-1}\right)$ and in group $2\left(16.7 \mathrm{ng} \cdot \mathrm{kg}^{-1} \cdot \mathrm{min}^{-1}\right)$. Saline was infused in group 3 (control group).

Blood samples were taken before starting the isotope infusion to determine baseline concentrations and background enrichment of glucose, glycerol, and palmitic acid. Blood samples for the enrichment were then taken at $105,110,115$, and $120 \mathrm{~min}$ to determine basal glucose and lipid kinetics (kinetics in period 1). After the start of TNF or saline infusion, blood samples were also taken at 140,160,180, 200, $220,225,230,235$, and $240 \mathrm{~min}$ to determine the response to TNF infusion (kinetics in period 2). The last four samples were used to determine glucose and lipid kinetics during TNF infusion. All samples were collected in 10-ml vacutainers containing lithium heparin and placed on ice. Plasma was separated by centrifuge at $4^{\circ} \mathrm{C}$ and frozen until further processing. Plasma samples for glucagon, insulin, and catecholamine determinations were collected at 120 and $240 \mathrm{~min}$. Plasma sample for glucagon and insulin were collected in vacutainers containing EDTA with and without aprotinin (Sigma Chemical Co., St. Louis, MO), respectively. Samples for catecholamine determination were collected in vacutainers containing EDTA and lithium heparin.

Analysis of samples. Plasma norepinephrine, epinephrine, and dopamine concentrations were determined by HPLC. The plasma insulin and glucagon concentrations were determined by radioimmunoassay. The plasma samples were stored at $-70^{\circ} \mathrm{C}$ until analysis. The plasma concentration of glucose was determined by a glucose autoanalyzer using the glucose oxidase reaction (Beckman Instruments, Inc., Fullerton, CA ). Plasma lactate concentration was determined by means of a lactate analyzer (Yellow Springs Instrument Co., Yellow Springs, $\mathrm{OH})$. Plasma triglyceride concentration was measured enzymatically (25) (RA-500; Technicon Instruments Corp., Tarrytown, NY). Blood for analysis of $\left[1-{ }^{13} \mathrm{C}\right]$ palmitic acid enrichment was collected and processed, as described previously (26). Briefly, the FFA were extracted from plasma and isolated by TLC, after which the methyl esters were made. Concentrations of palmitic acid and total FFA were determined by gas chromatography (model 5985; Hewlett-Packard Co., Palo Alto, CA) using heptadecanoic acid (C-17) as an internal standard. The concentration of palmitic acid in the infusion mixture was also determined by gas chromatography. Isotopic enrichment of palmitic acid was de- 
termined by gas chromatography-mass spectrometry (GCMS) (model 5992; Hewlett-Packard Co.). Ions of mass/charge ratio (m/e) 270 and 271 were selectively monitored in the electron impact ionization mode for the ultimate computation of the tracer/tracee ratio.

Glycerol enrichment was also determined by GCMS. Before processing the plasma, $0.00198 \mu \mathrm{mol}$ of $\left[2-{ }^{13} \mathrm{C}\right]$ glycerol was added to $1 \mathrm{ml}$ of all samples, except the background samples, as an internal standard to quantify the glycerol concentration. The plasma proteins were precipitated with barium hydroxide and zinc sulfate and the supernatant was passed through a mixed-bed anion-cation exchange resin column (Dowex AG-1-X8 and AG-50-W-X8, 200-400 mesh; Bio-Rad Laboratories, Richmond, $\mathrm{CA}$ ) and the trimethylsilyl derivative of glycerol was made. GCMS analysis was used with electronic impact ionization and ions were selectively monitored at $\mathrm{m} / \mathrm{e} 205,206$, and 208 (27). The apparent enrichment at $\mathrm{m} / \mathrm{e} 208$ was corrected for the contribution of the internal standard. Glucose enrichment was determined as previously described (27). Plasma samples were processed with same procedure as glycerol and subsequently reacted with acetic anhydride and pyridine to form the penta-acetate derivative. GCMS was used with electronic impact ionization, selectively monitoring ions at $\mathrm{m} / \mathrm{e} 202$, 201 , and 200 to determine the enrichment of [6,6- $\left.d_{2}\right]$ glucose. Correction was made for the contribution of the singly labeled molecule $(\mathrm{m} / \mathrm{e}$ 201 ) to the apparent enrichment at $\mathrm{m} / \mathrm{e} 202$. To analyze [2-d $\mathrm{d}_{1}$ glucose enrichment, the trimethylsilyl derivative was made and ions were monitored at $\mathrm{m} / \mathrm{e} 205$ and 204.

Calculations. The rate of appearance of palmitic acid (Ra palmitate), glycerol ( Ra glycerol), and glucose ( Ra glucose) in plasma were calculated as described by Steele (28). During the basal period (period 1), a physiological and isotopic steady state was present so that

$\operatorname{Ra}\left(\mu \mathrm{mol} \cdot \mathrm{kg}^{-1} \cdot \min ^{-1}\right)=F / I E$,

where $F$ is the isotopic infusion rate $\left(\mu \mathrm{mol} \cdot \mathrm{kg}^{-1} \cdot \mathrm{min}^{-1}\right)$ and $I E$ is the isotopic enrichment at plateau (tracer/tracee ratio).

After the administration of TNF (period 2), the steady state was disturbed. In this case, the non-steady state form of the Steele equation was used (28)

$\mathrm{Ra}=\frac{F-V\left[\left(C_{2}+C_{1}\right) / 2\right]\left[\left(E_{2}-E_{1}\right) /\left(t_{2}-t_{1}\right)\right]}{\left(E_{1}+E_{2}\right) / 2}$,

where $C_{2}$ and $C_{1}$ are the concentrations at times $(t) 2$ and 1 , respectively, and $V$ is the "effective volume of distribution" of the substrate. Spline curve fitting, a technique that smoothly joins polynomial function segments, was used in describing the tracer/tracee ratio and substrate concentration data (29). The effective volumes of distribution used for palmitate and glycerol were 40 and $160 \mathrm{ml} / \mathrm{kg}$, respectively. Validation of the calculation of substrate flux using stable isotopes has been described elsewhere in detail (30).

Metabolic clearance rate of glucose (MCR glucose) was calculated by dividing $\mathrm{Ra}$ of $\left[6,6-\mathrm{d}_{2}\right.$ ]glucose by the corresponding plasma glucose concentration. Normalizing glucose uptake by concentration to calculate MCR is not entirely valid, since these two factors are not linearly related over a wide range of concentrations and uptake rates (31). Nonetheless, under the conditions of this experiment, it is a useful expression of the effect of TNF on the relative ability of tissues to remove glucose from the plasma.

The concentration of plasma glycerol $(\mu \mathrm{mol} / \mathrm{ml})$ was determined as follows:

Plasma glycerol $=\frac{0.00198}{I E}$,

when $0.00198 \mu \mathrm{mol}$ of $\left[2-{ }^{13} \mathrm{C}\right]$ glycerol was added to each $1-\mathrm{ml}$ plasma sample, and $I E$ is the tracer/tracee ratio.

Total fat oxidation, carbohydrate oxidation, and resting energy expenditure were calculated from oxygen consumption, carbon dioxide production, and urinary nitrogen excretion using stoichiometric equations (32). Palmityl-stearyl-oleyl triglyceride $\left(\mathrm{C}_{55} \mathrm{H}_{104} \mathrm{O}_{6}\right)$ was considered to be a typical triglyceride (33) and total fatty acid oxidation was determined by dividing total triglyceride oxidation by 3 . In this study, urinary nitrogen excretion was assumed to be constant $(0.135$ $\left.\mathrm{mg} \cdot \mathrm{kg}^{-1} \cdot \mathrm{min}^{-1}\right)$.

The rate of appearance of FFA (Ra FFA) was calculated by dividing $\mathrm{Ra}$ palmitate by the ratio of palmitate concentration/total FFA concentration.

The rate of TG-FA cycling was calculated using both isotopic data and indirect calorimetry. Intraadipocyte TG-FA cycling occurs when FFAs released intracellularly during lipolysis are reesterified to triglyceride within adipocytes. Extraadipocyte TG-FA cycling occurs when FFAs and glycerol released into the bloodstream are reesterified in the liver. Extraadipocyte TG-FA cycling occurs when the triglyceride formed by fatty acid reesterification in the liver is released into the bloodstream and subsequently hydrolyzed by LPL and reesterified back to triglyceride again within the adipose tissue. Extraadipocyte TG-FA cycling thus ultimately involves recycling of fatty acid within the adipocyte, but the fatty acids transit through the plasma and then back to the adipocyte.

The rates of intraadipocyte and extraadipocyte recycling ( $\mu \mathrm{mol}$ fatty acid $\cdot \mathrm{kg}^{-1} \cdot \mathrm{min}^{-1}$ ) were calculated as follows:

Intraadipocyte recycling $=3 \times$ Ra glycerol $-\mathrm{Ra}$ FFA

Extraadipocyte recycling $=$ Ra FFA - Total fat oxidation

Total TG-FA cycling $=3 \times \mathrm{Ra}$ glycerol - Total fat oxidation.

We have previously discussed in detail the validity of the assumptions underlying these calculations (21).

The rate of glucose substrate cycling $\left(\mu \mathrm{mol} \cdot \mathrm{kg}^{-1} \cdot \min ^{-1}\right)$ was calculated as follows:

Glucose cycling $=R a\left(2-d_{1}\right)-R a\left(6,6-d_{2}\right)$,

where $R a\left(2-d_{1}\right)$ is the Ra glucose as calculated by the [2- $\mathrm{d}_{1}$ ] glucose and $R a\left(6,6-d_{2}\right)$ is the $R$ a glucose as calculated by the $\left[6,6-d_{2}\right]$ glucose.

Statistical analysis. All data are presented as means \pm SEM. The paired Student's $t$ test between periods 1 and 2 in the control and TNF groups was used to test the significance of difference. Linear-regression analysis and $t$ test were used to test the statistical significance of the correlation between cardiac index and rate of appearance. Fisher's $Z$ transformation test was used to compare the extent of the correlation of these parameters (34). $P<0.05$ was considered statistically significant.

\section{Results}

All three groups were similar with respect to total body weight (group 1 mean $=18.3 \mathrm{~kg}$ [range 14.5-22.7]; group 2 mean $=17.7 \mathrm{~kg}$ [range 12.7-20.9]; group 3 mean $=18.1 \mathrm{~kg}$ [range 14.1-21.8]). Hemodynamic and metabolic parameters of the control group did not significantly change throughout the experiment, so all comparisons were made between periods 1 and 2 in TNF-infused animals.

TNF infusion caused a significant reduction in pulmonary arterial pressure in both the high-dose $(P<0.001)$ and the low-dose groups $(P<0.01)$ ( Table I and Fig. 2$)$. TNF infusion also caused a significant fall in mean arterial pressure by $15 \%$ $(P<0.01)$ in the high-dose group and by $14 \%(P<0.05)$ in the low-dose group ( Table I and Fig. 2). High-dose infusion caused a $20 \%$ reduction of cardiac index $(\mathrm{CI})(P<0.05)$, but the low-dose TNF infusion caused only a $5 \%$ reduction of $\mathrm{CI}$, which was not statistically significant ( $P=0.507)$ (Table I and Fig. 2). TPRI did not change significantly in either TNF infusion group (Table I), and no animals in either group died or exhibited responses characteristic of the shock state.

The effects of TNF infusion on Ra of palmitate, FFA, and glycerol are shown in Table II and Figs. 3 and 4. Ra of palmitic 
Table I. Effects of TNF Infusion on Hemodynamic Parameters

\begin{tabular}{|c|c|c|c|c|c|c|}
\hline Group & $\begin{array}{l}\text { Measurement } \\
\text { interval }\end{array}$ & PAP & MAP & $\mathrm{CO}$ & CI & TPRI \\
\hline & & $m m H g$ & $m m H g$ & liter/min & liter $\cdot \min ^{-1} \cdot \mathrm{m}^{-2}$ & $d y n \cdot s \cdot \mathrm{cm}^{-5} \cdot \mathrm{m}^{-2}$ \\
\hline Control (saline) & Period $1^{\S}$ & $25 \pm 1$ & $155 \pm 6$ & $4.34 \pm 1.94$ & $5.32 \pm 0.41$ & $2,396 \pm 19$ \\
\hline$n=5$ & Period 2" & $25 \pm 2$ & $159 \pm 8$ & $3.89 \pm 1.74$ & $4.81 \pm 0.30$ & $2,686 \pm 201$ \\
\hline TNF (low dose)* & Period 1 & $19 \pm 1$ & $150 \pm 7$ & $3.77 \pm 0.39$ & $4.77 \pm 0.32$ & $2,671 \pm 285$ \\
\hline$n=6$ & Period 2 & $14 \pm 1^{* *}$ & $129 \pm 6 \neq \ddagger$ & $3.50 \pm 0.52$ & $4.42 \pm 0.58$ & $2,570 \pm 433$ \\
\hline TNF (high dose) f $^{\ddagger}$ & Period 1 & $25 \pm 4$ & $163 \pm 5$ & $3.58 \pm 0.45$ & $4.40 \pm 0.24$ & $3,034 \pm 23$ \\
\hline$n=8$ & Period 2 & $19 \pm 4^{\prime}$ & $138 \pm 10^{* *}$ & $2.88 \pm 0.29^{\ddagger \ddagger}$ & $3.55 \pm 0.24^{\ddagger \ddagger}$ & $3,179 \pm 347$ \\
\hline
\end{tabular}

All values presented are means \pm SEM. $P A P$, pulmonary arterial pressure; $M A P$, mean arterial pressure; $C O$, cardiac output; $C I$, cardiac index . ${ }^{*} 3.5 \mu \mathrm{g} / \mathrm{kg} ;{ }^{\ddagger} 10 \mu \mathrm{g} / \mathrm{kg} ;{ }^{\S}$ basal period; "TNF infusion period; ' $P<0.001$ vs. basal value; ${ }^{* *} P<0.01$ vs. basal value; ${ }^{\ddagger \ddagger} P<0.05$ vs. basal value.

acid decreased significantly by $42 \%(P<0.01)$ in the high-dose TNF infusion group and by $20 \%(P<0.05)$ in the low-dose TNF infusion group (Table II and Fig. 3). Similarly, Ra FFA was significantly decreased by $46 \%(P<0.05)$ and by $19 \%$ in the high-dose and the low-dose TNF infusion groups, respectively (Table II and Fig. 4). The high-dose TNF infusion significantly decreased $\mathrm{Ra}$ glycerol by $28 \%(P<0.05)$ and the low-
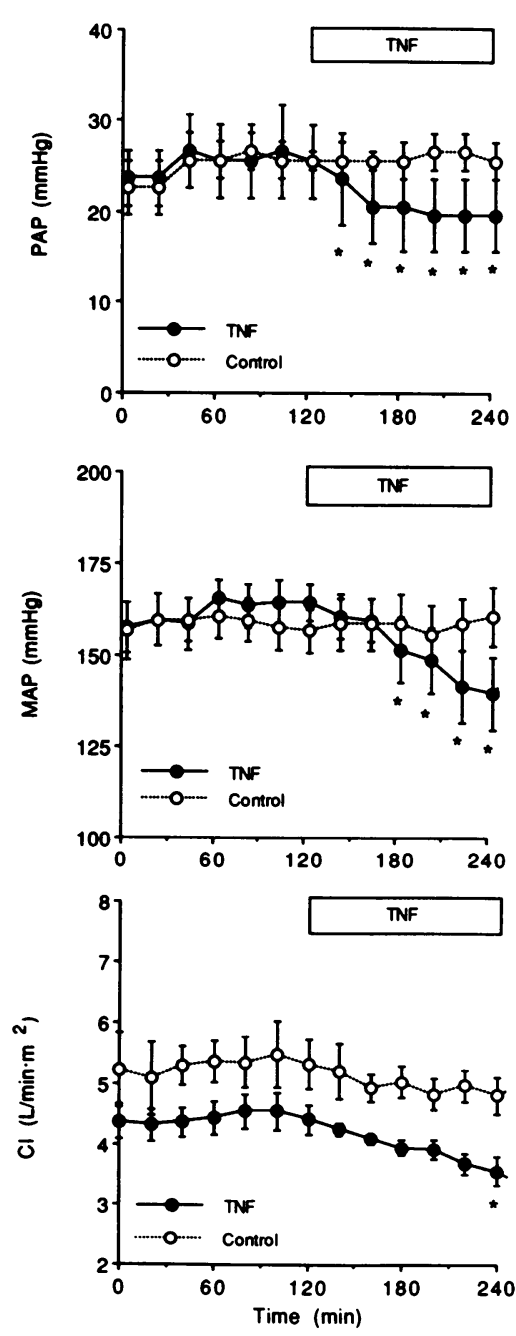

Figure 2. High-dose TNF-induced changes of pulmonary arterial pressure (top), mean arterial pressure ( middle), and $\mathrm{CI}$ ( bottom) in periods 1 and 2. Control group (open circles) and high-dose TNF group (filled circles). Data are means \pm SEM. ${ }^{*} P<0.05$ vs. basal value. dose infusion caused a $13 \%$ reduction in Ra glycerol (Table II and Fig. 4). The magnitude of the effect of TNF infusion on the $\mathrm{Ra}$ of palmitic acid during the high-dose TNF infusion was greater than that on the Ra glycerol (Fig. 4). This difference reflected an $23 \%$ increase in intraadipocyte TG-FA cycling by the high-dose TNF infusion (Table III), but the difference was not statistically significant. In contrast, extraadipocyte TG-FA cycling decreased from $1.50 \pm 2.57 \mu \mathrm{mol} \cdot \mathrm{kg}^{-1} \cdot \mathrm{min}^{-1}$ in the basal period (period 1) to $-0.18 \pm 1.78 \mu \mathrm{mol} \cdot \mathrm{kg}^{-1} \cdot \mathrm{min}^{-1} \mathrm{dur}$ ing the high-dose TNF infusion period (period 2 ). Total TGFA recycling fell by $27 \%$ during the high-dose TNF infusion (Table III).

There was a significant correlation between percent change of $\mathrm{CI}$ and percent change of $\mathrm{Ra}$ palmitate ( $\triangle \mathrm{Ra}$ palmitate) for all animals infused with TNF $(P<0.0001, r=0.69)$, Ra FFA ( $\triangle \mathrm{Ra} F F A)(P<0.0001, r=0.60)$, and Ra glycerol $(\Delta \mathrm{Ra}$ glycerol ) $(P=0.0329, r=0.36)$ (Fig. 5). The correlation between $\Delta \mathrm{CI}$ and $\Delta \mathrm{Ra}$ palmitate was greater than the correlation between $\Delta \mathrm{CI}$ and $\Delta \mathrm{Ra}$ glycerol $(P=0.028$ by Fisher's $\mathrm{Z}$ transformation).

The change in Ra glycerol and Ra FFA caused corresponding changes in plasma concentrations (Table IV). Glycerol concentration fell by $26 \%$ in the high-dose TNF group and by $22 \%$ in the low-dose TNF group, but the difference was not

Table II. Effect of TNF on Glycerol and FFA Release

\begin{tabular}{lcccc}
\hline \multicolumn{1}{c}{ Group } & $\begin{array}{c}\text { Measurement } \\
\text { interval }\end{array}$ & Ra palmitate & Ra FFA & Ra glycerol \\
\hline & & & $\mu \mathrm{mol} \cdot \mathrm{kg}^{-1} \cdot \mathrm{min}^{-1}$ \\
& & & & \\
Control & Period 1 & $2.61 \pm 0.14$ & $11.72 \pm 1.23$ & $4.69 \pm 0.44$ \\
$\quad$ (saline) & Period 2 & $2.93 \pm 0.39$ & $14.52 \pm 2.93$ & $5.32 \pm 0.72$ \\
$n=5$ & & & & \\
TNF & Period 1 & $2.20 \pm 0.25$ & $8.05 \pm 1.53$ & $3.57 \pm 0.83$ \\
$\quad$ (low dose) & Period 2 & $1.75 \pm 0.20^{\ddagger}$ & $6.56 \pm 1.59$ & $3.11 \pm 0.31$ \\
$n=6$ & & & & \\
TNF & Period 1 & $1.86 \pm 0.28$ & $8.88 \pm 1.44$ & $3.62 \pm 0.44$ \\
$\quad$ (high dose) & Period 2 & $1.07 \pm 0.20^{*}$ & $4.83 \pm 0.92^{\ddagger}$ & $2.60 \pm 0.68^{\ddagger}$ \\
$n=8$ & & & & \\
& & & &
\end{tabular}

All values presented are means \pm SEM. ${ }^{*} P<0.01$ vs. basal value; ${ }^{\ddagger} P<0.05$ vs. basal value. 


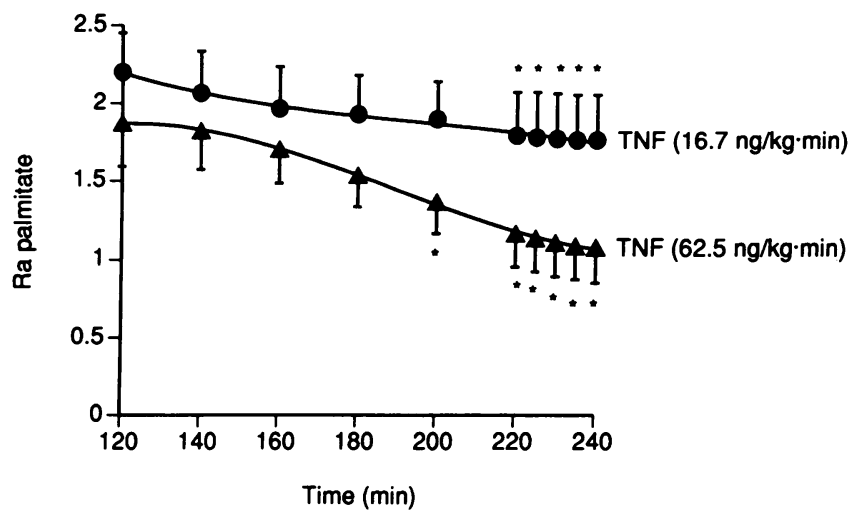

Figure 3. Effect of two different doses of TNF on Ra palmitate. Data are means \pm SEM. ${ }^{*} P<0.05$ vs. basal value.

statistically significant. The FFA concentration fell by $33 \%$ in the high-dose TNF group and by $28 \%$ in low-dose TNF group. Plasma triglyceride concentration did not change significantly during TNF infusion (Table IV).

The high-dose TNF infusion produced a significant decrease below basal value $(P<0.05)$ in plasma glucose concentration and also in the low-dose TNF group $(P<0.05)$ (Table V). High-dose of TNF infusion caused a significant increase $(P$ $<0.05$ ) in plasma lactate concentration and no significant change was seen in the low-dose TNF group (Table V). As shown in Fig. 6, the plasma glucose level in the high-dose TNF group decreased $10 \%$ below the basal value $40 \mathrm{~min}$ after the start of TNF infusion. Plasma lactate in the high-dose TNF group rapidly increased and remained $40-55 \%$ above basal value. Ra glucose in the high-dose TNF group was significantly elevated by $13 \%(P<0.05)$ (Table VI). However, low-dose TNF infusion did not increase Ra glucose. Glucose cycling was also increased by $106 \%$ in the high-dose TNF group, but not

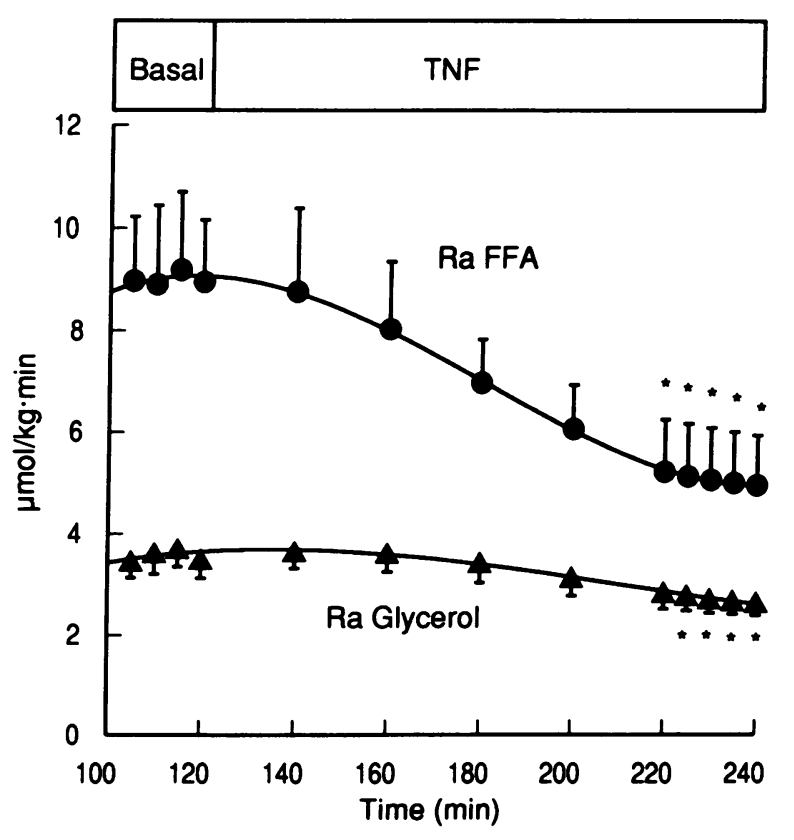

Figure 4. Effect of high-dose TNF on Ra FFA and Ra glycerol. Data are means \pm SEM. ${ }^{*} P<0.05$ vs. basal value.
Table III. Effect of TNF on TG-FA Cycling

\begin{tabular}{lcccc}
\hline Group & $\begin{array}{c}\text { Measurement } \\
\text { interval }\end{array}$ & $\begin{array}{c}\text { Intraadipocyte } \\
\text { cycling }\end{array}$ & $\begin{array}{c}\text { Extraadipocyte } \\
\text { cycling }\end{array}$ & $\begin{array}{c}\text { Total TG-FA } \\
\text { cycling }\end{array}$ \\
\hline & & \multicolumn{4}{c}{$\mu \mathrm{mol}$ fatty acid $\cdot \mathrm{kg}^{-1} \cdot \mathrm{min}^{-1}$} \\
TNF & Period 1 & $2.56 \pm 0.80$ & $1.50 \pm 2.57$ & $4.06 \pm 2.70$ \\
(high dose) & Period 2 & $3.15 \pm 0.54$ & $-0.18 \pm 1.78$ & $2.97 \pm 1.74$ \\
$n=8$ & & & & \\
\hline
\end{tabular}

All values presented are means \pm SEM.

significantly $(P>0.05)$ (Table VI). MCR glucose in the highdose TNF group was significantly increased by $25 \%(P<0.01)$ (Table VI) and by $10 \%$ in the low-dose TNF group.

The indirect calorimetry data are shown in Table VII. High-dose TNF infusion caused no significant difference in oxygen consumption, $\mathrm{CO}_{2}$ production, or resting energy expenditure. Total fat oxidation significantly decreased by $23 \%$ in the high-dose TNF group $(P<0.05)$ since the high-dose TNF infusion caused a significant elevation in respiratory quotient $(P<0.05)$. Carbohydrate oxidation was increased from $16.9 \pm 4.1 \mu \mathrm{mol} \cdot \mathrm{kg}^{-1} \cdot \mathrm{min}^{-1}$ in the basal period (period 1) to $23.3 \pm 6.8 \mu \mathrm{mol} \cdot \mathrm{kg}^{-1} \cdot \mathrm{min}^{-1}$ in the high-dose TNF group.

Plasma concentrations of insulin, glucagon, and catecholamines in the high-dose TNF group are shown in Table VIII. The plasma glucagon level significantly increased by $89 \%$ in
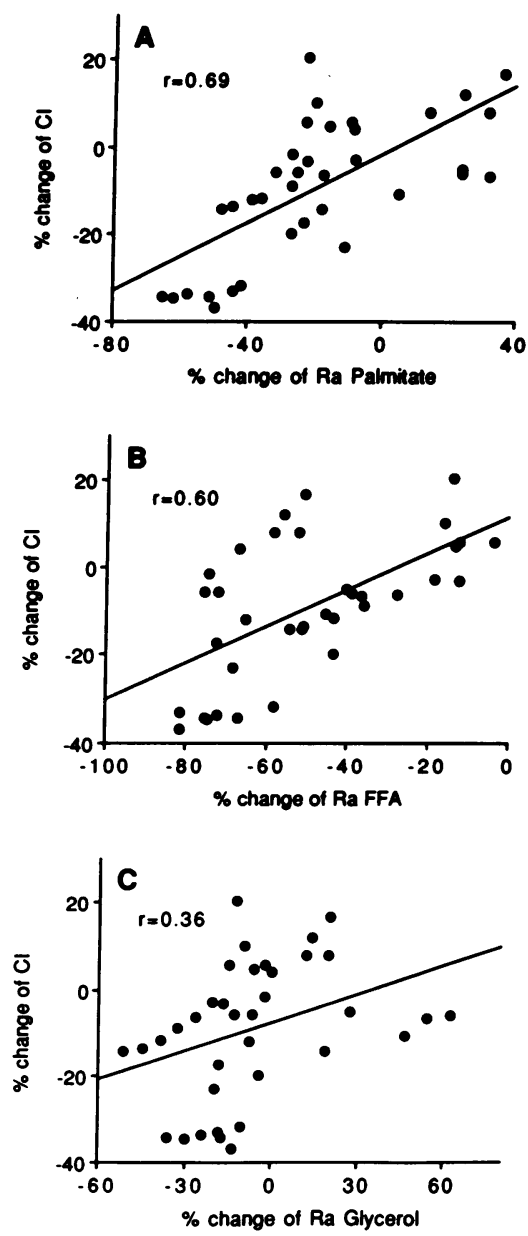

Figure 5. Correlation between $\mathrm{CI}$ and substrate kinetics. $(A)$ Percent change of $\mathrm{CI}$ vs. percent change of $\mathrm{Ra}$ palmitate; $(B)$ percent change of $C I$ vs. percent change of Ra FFA; $(C)$ percent change of cardiac index vs. percent change of $\mathrm{Ra}$ glycerol. 
Table IV. Effect of TNF on Glycerol, Palmitate, FFA, and Triglyceride Concentration

\begin{tabular}{cccccc}
\hline Group & $\begin{array}{c}\text { Measurement } \\
\text { interval }\end{array}$ & Glycerol & Palmitate & FFA & TG \\
& & & $\mu m o l / m l$ & & \\
& & & $0.13 \pm 0.02$ & $0.57 \pm 0.05$ & $21.0 \pm 3.8$ \\
Control (saline) & Period 1 & $0.05 \pm 0.01$ & $0.13 \pm 0.01$ & $0.52 \pm 0.03$ & $19.0 \pm 3.1$ \\
$n=5$ & Period 2 & $0.06 \pm 0.01$ & $0.11 \pm 0.02$ & $0.39 \pm 0.09$ & ND \\
TNF (low dose) & Period 1 & $0.04 \pm 0.009$ & $0.09 \pm 0.04$ & $0.28 \pm 0.05$ & ND \\
$n=6$ & Period 2 & $0.03 \pm 0.005$ & $0.09 \pm 0.06$ & $0.40 \pm 0.08$ & $29.3 \pm 3.1$ \\
TNF (high dose) & Period 1 & $0.04 \pm 0.005$ & $0.27 \pm 0.05^{*}$ & $27.5 \pm 2.1$ \\
$n=8$ & Period 2 & $0.03 \pm 0.003$ & $0.06 \pm 0.04$ & & \\
\hline
\end{tabular}

All values presented are means \pm SEM. ND, not done; $T G$, triglyceride. ${ }^{*} P<0.05$ vs. basal value.

period $2(P<0.01)$. There was no significant difference in plasma insulin and catecholamine concentrations.

\section{Discussion}

Despite considerable recent research on the role of TNF in pathophysiology, its effect on energy substrate kinetics is not yet clear. In this study, we have documented that TNF, given in a dose designed to parallel what might be encountered in response to infection, caused a shift towards carbohydrate metabolism. Glucose oxidation increased owing to increased availability (production), whereas fat availability and oxidation fell. These responses could be explained at least in part by the changes in hormone concentrations. Glucagon significantly increased, and it is well established that glucagon is the predominant stimulator of the accelerated rate of glucose production in sepsis $(35,36)$. On the other hand, adrenergic activity has been shown to be the most important stimulator of lipolysis (36), and thus in the absence of a change in catecholamine concentration, a stimulation of lipolysis would not have been expected.

Whereas all the data from our experiment are consistent with the notion that TNF causes a shift towards carbohydrate metabolism, these responses were somewhat unexpected, given the previously published literature. TNF is proposed to be an important mediator of many aspects of the response to endotoxin and sepsis $(13,37)$. However, increased lipolysis is commonly seen in septic humans (3) and dogs (38). Furthermore, TNF infusion caused an increase in FFA flux in some (but not all) patients with cancer (18), yet in our experiment, lipolysis

Table V. Effect of TNF on Glucose and Lactate Concentration

\begin{tabular}{|c|c|c|c|}
\hline Group & $\begin{array}{l}\text { Measurement } \\
\text { interval }\end{array}$ & Glucose & Lactate \\
\hline & & \multicolumn{2}{|c|}{$\mu \mathrm{mol} / \mathrm{ml}$} \\
\hline Control (saline) & Period 1 & $6.15 \pm 0.29$ & $0.37 \pm 0.06$ \\
\hline$n=5$ & Period 2 & $6.04 \pm 0.23$ & $0.32 \pm 0.05$ \\
\hline TNF (low dose) & Period 1 & $6.13 \pm 0.16$ & $0.47 \pm 0.05$ \\
\hline$n=6$ & Period 2 & $5.74 \pm 0.24^{*}$ & $0.75 \pm 0.18$ \\
\hline TNF (high dose) & Period 1 & $6.36 \pm 0.24$ & $0.70 \pm 0.10$ \\
\hline$n=8$ & Period 2 & $5.80 \pm 0.24^{*}$ & $1.04 \pm 0.17^{*}$ \\
\hline
\end{tabular}

Values are means \pm SEM. ${ }^{*} P<0.05$ vs. basal value. (both Ra glycerol and Ra FFA) was significantly reduced in a dose-dependent manner. One possible explanation is that the dose of TNF we infused was below the dose needed in humans to elicit a stimulation of lipolysis. However, the high-dose TNF infusion was selected as appropriate to mimic the concentration that would be anticipated during systemic infection (37) and, as cited above, systemic infection would be anticipated to cause a stimulation of lipolysis. The fact that we observed a significant fall in both cardiac output and arterial blood pressure with the high dose indicates that in fact our dose was adequate to cause at least some of the responses normally seen in response to endotoxin. Furthermore, the fact that the lowdose TNF infusion caused changes similar in all respects, except magnitude, to the high-dose effects further argues against the likelihood of different responses being obtained with a high-dose TNF infusion.

One possible explanation for the inhibition of Ra palmitate and FFA by TNF infusion is a decline in adipose tissue blood flow resulting from the decrease in cardiac output. When all results were taken together, there was a significant correlation
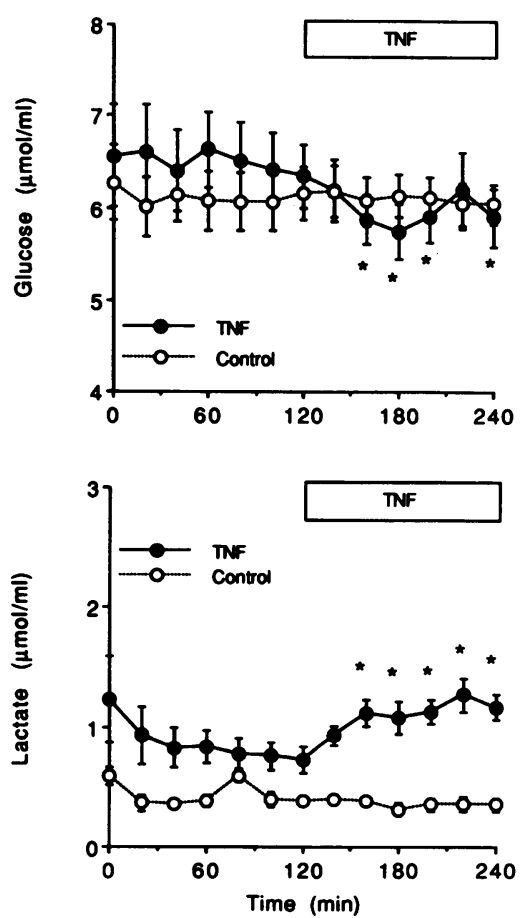

Figure 6. Effect of TNF on plasma glucose (top) and lactate (bottom) concentration in control group (open circles) and high-dose TNF group (filled circles). Data are mean \pm SEM. ${ }^{*} P<0.05$ vs. basal value. 
Table VI. Effect of TNF on Glucose Production, Glucose Clearance, and Glucose Cycling

\begin{tabular}{lcccc}
\hline \multicolumn{1}{c}{ Group } & $\begin{array}{c}\text { Measurement } \\
\text { interval }\end{array}$ & Ra glucose & MCR glucose & $\begin{array}{c}\text { Glucose } \\
\text { cycling }\end{array}$ \\
\hline & & $\mu \mathrm{mol} \cdot \mathrm{kg}^{-1} \cdot \mathrm{min}^{-1}$ & $\mathrm{ml} \cdot \mathrm{kg}^{-1} \cdot \mathrm{min}^{-1}$ & \\
Control & Period 1 & $14.6 \pm 0.1$ & $2.37 \pm 0.10$ & $4.90 \pm 1.51$ \\
$\quad$ (saline) & Period 2 & $13.8 \pm 1.1$ & $2.24 \pm 0.17$ & $4.64 \pm 1.15$ \\
$\quad n=5$ & & & & \\
TNF & Period 1 & $12.9 \pm 0.8$ & $2.10 \pm 0.13$ & ND \\
$\quad$ low dose) & Period 2 & $13.0 \pm 0.9$ & $2.31 \pm 0.21$ & ND \\
$n=6$ & & & & \\
TNF & Period 1 & $18.1 \pm 1.1$ & $2.84 \pm 0.16$ & $5.13 \pm 2.06$ \\
(high dose) & Period 2 & $20.7 \pm 1.9 *$ & $3.55 \pm 0.33^{\ddagger}$ & $10.58 \pm 4.30$ \\
$n=8$ & & & & \\
& & & &
\end{tabular}

All values presented are means \pm SEM. $N D$, not done. ${ }^{*} P<0.05$ vs. basal value. ${ }^{\ddagger} P<0.01$ vs. basal value.

between $\Delta \mathrm{CI}$ and $\Delta \mathrm{Ra}$ palmitate (Fig. 5), $\Delta \mathrm{Ra}$ FFA (to a lesser extent), and $\Delta \mathrm{Ra}$ glycerol. Since the FFA is not water soluble, Ra FFA may be limited by the availability of albumin-binding sites in the plasma in conditions of low adipose tissue blood flow (39). On the other hand, since glycerol is water soluble and its diffusion from adipose cell is not limited by the availability of albumin-binding sites in the plasma, it has generally been considered that $\mathrm{Ra}$ glycerol is not dependent on blood flow to the adipose cell. Consistent with this concept, the correlation between $\Delta \mathrm{CI}$ and $\Delta \mathrm{Ra}$ palmitate was greater than the correlation between $\Delta \mathrm{CI}$ and $\Delta \mathrm{Ra}$ glycerol. However, the reason for the weak correlation between $\Delta \mathrm{CI}$ and $\Delta \mathrm{Ra}$ glycerol is not clear. It is possible that TNF has a direct dose-dependent inhibitory effect on lipolysis and on $\mathrm{CI}$, therefore, the correlation of the two factors reflects two distinct effects of TNF, rather than a cause and effect relation of $\mathrm{CI}$ on $\mathrm{Ra}$ glycerol.

The other possible explanation for the inhibition of lipolysis in this study and the generally encountered stimulation of lipolysis in sepsis is a difference in the adrenergic response. In this study, TNF infusion apparently did not cause an increase in adrenergic stimulation, as indicated by relatively constant plasma catecholamine concentrations. In contrast to the results of our study, in other studies of sepsis, adrenergic activity was increased (40) and beta-adrenergic blockade caused lipolysis to return to the normal rate (41). Although catecholamines were not measured in the study in cancer patients in which TNF was found to occasionally stimulate lipolysis (18), the increase in heart rate and oxygen consumption observed was consistent with enhanced adrenergic stimulation. Furthermore, catecholamines increased in normal volunteers given TNF (42). Thus, it seems that there is no direct effect of TNF to stimulate lipolysis, and TNF may actually inhibit lipolysis. This observation is consistent with data from in vitro experiments (43).

The so-called TG-FA cycle has been shown to be important in regulating several aspects of lipid kinetics in vivo (44). Within the adipocyte, the extent of reesterification determines the relationship between lipolysis and the rate of release of FFA into the plasma. During TNF infusion, the intraadipocyte recycling of fatty acids increased, meaning that the release of fatty acids was decreased to a considerably greater extent than was the rate of lipolysis. The most likely explanation is that the decrease in cardiac output, coupled with a shunting of blood flow away from the fat, decreased albumin flow through the adipose tissue to the point where the availability of fatty acidbinding sites on albumin was limiting for the release of FFA into plasma. It is also possible that the increased glucose production during TNF infusion resulted in increased uptake of glucose in the adipocytes. We have previously shown that the availability of alpha-glycerol phosphate derived from plasma glucose is rate limiting in the process of reesterification of FFA within the adipocyte (45).

The reesterification in the form of fatty acids released from the adipocytes into the plasma is termed extraadipocyte cycling, in that the fatty acids have passed through the plasma compartment in the process of recycling back into triglyceride. This extraadipocyte recycling of fatty acids is normally the major pathway of hepatic triglyceride synthesis (46); de novo hepatic fatty acid synthesis normally does not occur to any significant extent, even in the fed state (47). Furthermore, in critically ill patients, hepatic triglyceride synthesis from FFA is increased by as much as fivefold (20). This contributes importantly to the development of fatty acid infiltration of the liver, which is common in all forms of critical illness, irrespective of the form of nutritional support. The primary basis for the increased hepatic triglyceride synthesis in patients is the pronounced stimulation of lipolysis in the absence of a corresponding increase in the requirement for energy substrates. In response to TNF, lipolysis was actually inhibited, and Ra FFA decreased to an even greater extent owing to increased intraadipocyte recycling, whereas the overall energy requirement (as determined by indirect calorimetry) remained constant. Consequently, hepatic triglyceride esterification of plasma FFA decreased significantly. Thus, the increased hepatic triglyceride synthesis from plasma FFA commonly observed in critically ill patients cannot be ascribed directly to TNF, but rather

Table VII. Effect of TNF on Energy Metabolism

\begin{tabular}{|c|c|c|c|c|c|c|}
\hline Group & $\begin{array}{l}\text { Measurement } \\
\text { interval }\end{array}$ & $\begin{array}{c}\text { Oxygen } \\
\text { consumption }\end{array}$ & $\begin{array}{c}\mathrm{CO}_{2} \\
\text { production }\end{array}$ & $\begin{array}{c}\text { Fat } \\
\text { oxidation }\end{array}$ & NPRQ & REE \\
\hline & & & $\mu \mathrm{mol} \cdot \mathrm{kg}^{-1} \cdot \mathrm{min}^{-1}$ & & & $\mathrm{cal} \cdot \mathrm{kg}^{-1} \cdot \mathrm{min}^{-1}$ \\
\hline Control (saline) & Period 1 & $406.6 \pm 57.9$ & $301.8 \pm 44.9$ & $12.8 \pm 1.7$ & $0.74 \pm 0.01$ & $42.9 \pm 6.1$ \\
\hline$n=5$ & Period 2 & $404.6 \pm 68.9$ & $300.1 \pm 52.7$ & $12.7 \pm 2.2$ & $0.74 \pm 0.01$ & $42.5 \pm 7.3$ \\
\hline TNF (high dose) & Period 1 & $334.6 \pm 24.7$ & $269.3 \pm 24.6$ & $7.60 \pm 0.7$ & $0.79 \pm 0.02$ & $35.3 \pm 2.9$ \\
\hline$n=8$ & Period 2 & $330.1 \pm 37.8$ & $278.5 \pm 40.3$ & $5.82 \pm 0.7^{*}$ & $0.83 \pm 0.03^{*}$ & $35.4 \pm 4.2$ \\
\hline
\end{tabular}

All values presented are means \pm SEM. $N P R Q$, nonprotein respiratory quotient; $R E E$, resting energy expenditure. ${ }^{*} P<0.05$ vs. basal value. 


\begin{tabular}{|c|c|c|c|c|c|c|}
\hline \multirow[b]{2}{*}{ Group } & \multirow{2}{*}{$\begin{array}{l}\text { Measurement } \\
\text { interval }\end{array}$} & \multirow[b]{2}{*}{ Glucagon } & \multirow[b]{2}{*}{ Insulin } & \multicolumn{3}{|c|}{ Catecholamine } \\
\hline & & & & Norepinephrine & Epinephrine & Dopamine \\
\hline & & $p g / m l$ & $\mu U / m l$ & & $p g / m l$ & \\
\hline Control (saline) & Period 1 & $133 \pm 11$ & $5.4 \pm 0.2$ & $218 \pm 25$ & $12 \pm 2$ & $83 \pm 25$ \\
\hline$n=5$ & Period 2 & $137 \pm 26$ & $5.0 \pm 0.0$ & $218 \pm 17$ & $14 \pm 4$ & $17 \pm 34$ \\
\hline TNF (high dose) & Period 1 & $105 \pm 13$ & $7.4 \pm 0.9$ & $202 \pm 8$ & $48 \pm 15$ & $40 \pm 10$ \\
\hline$n=8$ & Period 2 & $198 \pm 35^{*}$ & $6.8 \pm 1.2$ & $115 \pm 26$ & $76 \pm 25$ & $44 \pm 13$ \\
\hline
\end{tabular}

All values presented are means \pm SEM. ${ }^{*} P<0.01$ vs. basal value.

appears to occur secondarily to increase Ra FFA stemming from increased adrenergic activity (20). Although our observation that TNF administration did not induce hypertriglyceridemia is consistent with other studies in dogs (48), this finding is different from results from human cancer patients (18), monkeys (49), and rats (19). These conflicting results may be partially explained by either species differences or dose of TNF given, that is, 20 and $125 \mu \mathrm{g} / \mathrm{kg}$ of TNF were administered in monkeys and in rats, respectively, which was 2- and 12-fold more than we used.

Increased glucose production and utilization are major features of the metabolic response to the infection $(1,2,50)$. Previous studies demonstrated that administration of TNF causes hypoglycemia (51), and this finding has been partially explained by the fact that TNF increases glucose utilization both in vitro $(52,53)$ and in vivo $(51,54,55)$, although there are conflicting results (56). The most striking aspect of the response to TNF in our study is the similarity to the response to glucagon infusion. Glucagon infusion stimulates glucose production and glucose cycling (21), and normalizing glucagon concentration in critically ill patients also normalizes the accelerated rate of glucose production (57). Lipolysis is slightly inhibited during glucagon infusion probably because of the effect of increased glucose production, and intraadipocyte TG-FA cycling is also increased significantly (21). Thus, it seems that the most important role of TNF in substrate metabolism may be to stimulate glucagon secretion. On the other hand, our study provides little support for the role of the catecholamines as mediators of the response to TNF. In contrast to endotoxin infusion in healthy subjects, in whom catecholamines increase at $2 \mathrm{~h}(58)$, we found no increase in catecholamines during TNF infusion.

Thus, we found a strong antilipolytic response to TNF infusion, which is in contrast to the stimulation of lipolysis seen in chronic sepsis. Glucose production was stimulated by TNF, in a manner similar to the septic response. We therefore cannot entirely attribute the response of substrate metabolism in sepsis to the direct (or even indirect) effects of TNF. Alterations in glucagon concentration and adipose tissue blood flow seem likely candidates as mediators of some aspects of the responses to TNF.

\section{Acknowledgment}

The authors thank Susan George and Guy Jones for their technical assistance. We are also grateful to Drs. Judah Rosenblatt and Lyle Broemeling for statistical consultations.
This study was supported by a grant from the Shriners Hospital for Crippled Children.

\section{References}

1. Long, C. L., J. L. Spencer, and J. M. Kinney. 1971. Carbohydrate metabolism in man: effect of elective operations and major trauma. J. Appl. Physiol. 31:110-116.

2. Wolfe, R. R., D. Elahi, and J. J. Spitzer. 1977. Glucose and lactate kinetics after endotoxin administration in dogs. Am. J. Physiol. 232:E180-E185.

3. Carpentier, Y. A., J. Askanazi, D. H. Elwyn, M. Jeevanandam, F. E. Gump, A. I. Hyman, R. Burr, and J. M. Kinney. 1979. Effect of hypercaloric glucose infusion on lipid metabolism in injury and sepsis. J. Trauma. 19:649-654.

4. Nordenström, J., Y. A. Carpentier, J. Askanazi, A. P. Robin, D. H. Elwyn, T. W. Hensle, and J. M. Kinney. 1983. Free fatty acid mobilization and oxidation during total parenteral nutrition in trauma and infection. Ann. Surg. 198:725735.

5. Beisel, W. R. 1981. The Science and Practice of Clinical Medicine. Grune and Stratton, New York. 28 pp.

6. Gallin, J. I., D. Kaye, and W. M. O'Leary. 1969. Serum lipids in infection. N. Engl. J. Med. 281:1081-1086.

7. Guckian, J. C. 1973. Role of metabolism in pathogenesis of bacteremia due to Diplococcus pneumoniae in rabbits. J. Infect. Dis. 127:1-8.

8. Wilmore, D. W., L. H. Aulick, A. D. Mason, and B. A. Pruitt. 1977. Influence of the burn wound on local and systemic responses to injury. Ann. Surg. 186:444-458.

9. Beutler, B., and A. Cerami. 1986. Cachectin and tumor necrosis factor as two sides of the same biological coin. Nature (Lond.). 320:584-588. 632 .

10. Old, L. J. 1985. Tumor necrosis factor. Science (Wash. DC). 230:630-

11. Carswell, E. A., L. J. Old, R. L. Kassel, S. Green, N. Fiore, and B. Williamson. 1975. An endotoxin-induced serum factor that causes necrosis of tumors. Proc. Natl. Acad. Sci. USA. 72:3666-3670.

12. Helson, L., S. Green, E. A. Carswell, and L. J. Old. 1975. Effect of tumor necrosis factor on cultured human melanoma cells. Nature (Lond.). 258:731732.

13. Beutler, B., I. W. Milsark, and A. Cerami. 1985. Passive immunization against cachectin/tumor necrosis factor protects mice from lethal effect of endotoxin. Science (Wash. DC). 229:869-871.

14. Tracey, K. J., B. Beutler, S. F. Lowry, J. Merryweather, S. Wolpe, I. W. Milsark, R. J. Hariri, T. J. Fahey III, A. Zentella, J. D. Albert, et al. 1986. Shock and tissue injury induced by recombinant human cachectin. Science (Wash. DC). $234: 470-474$.

15. Kawakami, M., P. H. Pekala, M. D. Lane, and A. Cerami. 1982. Lipoprotein lipase suppression in 3T3-L1 cells by an endotoxin-induced mediator from exudate cells. Proc. Natl. Acad. Sci. USA. 79:912-916.

16. Kern, P. A. 1988. Recombinant human tumor necrosis factor does not inhibit lipoprotein lipase in primary cultures of isolated human adipocytes. $J$ Lipid. Res. 29:909-914.

17. Pekala, P. H., M. Kawakami, C. W. Angus, M. D. Lane, and A. Cerami 1983. Selective inhibition of synthesis of enzymes for de novo fatty acid biosynthesis by an endotoxin induced mediator from exudate cells. Proc. Natl. Acad. Sci. USA. 80:2743-2747.

18. Starnes, H. F., Jr., R. S. Warren, M. Jeevanandam, J. L. Gabrilove, W. Larchian, H. F. Oettgen, and M. F. Brennan. 1988. Tumor necrosis factor and the acute metabolic response to tissue injury in man. $J$. Clin. Invest. 82:1321-1325.

19. Feingold, K. R., and C. Grunfeld. 1987. Tumor necrosis factor-alpha stimulates hepatic lipogenesis in the rat in vivo. J. Clin. Invest. 80:184-190. 
20. Wolfe, R. R., D. N. Herndon, F. Jahoor, H. Miyoshi, and M. Wolfe. 1987. Effect of severe burn injury on substrate cycling by glucose and fatty acids. $N$. Engl. J. Med. 317:403-408

21. Miyoshi, H., G. I. Shulman, E. J. Peters, M. H. Wolfe, D. Elahi, and R. R Wolfe. 1988. Hormonal control of substrate cycling in humans. J. Clin. Invest. 81:1545-1555.

22. Wolfe, R. R., S. Klein, F. Carraro, and J. M. Weber. 1990. Role of triglyceride-fatty acid cycle in controlling fat metabolism in humans during and afte exercise. Am. J. Physiol. 258:E382-E389.

23. Shulman, G. I., P. W. Ladenson, M. H. Wolfe, E. C. Ridgway, and R. R. Wolfe. 1985. Substrate cycling between gluconeogenesis and glycolysis in euthyroid, hypothyroid, and hyperthyroid man. J. Clin. Invest. 76:757-764.

24. Traber, D. L., H. Redl, G. Schlag, D. N. Herndon, R. Kimura, T. Prien, and L. D. Traber. 1988. Cardiopulmonary responses to continuous administration of endotoxin. Am. J. Physiol. 254:H833-H839.

25. Fossati, P., and L. Prencipe. 1982. Serum triglycerides determined colorimetrically with an enzyme that produces hydrogen peroxide. Clin. Chem 28:2077-2080.

26. Wolfe, R. R., J. E. Evans, C. J. Mullany, and J. F. Burke. 1980. Measurement of plasma free fatty acid turnover and oxidation using $\left[1-{ }^{13} \mathrm{C}\right]$ palmitic acid. Biomed. Mass Spectrom. 7:168-171.

27. Wolfe, R. R. 1985. Tracers in Metabolic Research: Radioisotope and Stable Isotope/Mass Spectrometry Methods. Alan R. Liss Inc., New York. 261 pp.

28. Steele, R. 1959. Influences of glucose loading and of injected insulin on hepatic glucose output. Ann. NY Acad. Sci. 82:420-430.

29. Wolfe, R. R., E. J. Peters, S. Klein, O. B. Holland, J. Rosenblatt, and H. Gary, Jr. 1987. Effect of short-term fasting on lipolytic responsiveness in normal and obese human subjects. Am. J. Physiol. 252:E189-E196.

30. Rosenblatt, J., D. Chinkes, M. Wolfe, and R. R. Wolfe. 1992. Stable isotope tracer analysis by GC-MS including quantification of isotopomer effects. Am. J. Physiol. 263:E584-E596.

31. Verdonk, C. A., R. A. Rizza, and J. E. Gerich. 1981. Effects of plasma glucose concentration on glucose utilization and glucose clearance in normal man. Diabetes. 30:535-537.

32. Frayn, K. N. 1983. Calculation of substrate oxidation rates in vivo from gaseous exchange. J. Appl. Physiol. 55:628-634.

33. Hirsch, J. 1965. Fatty acid patterns in human adipose tissue. In Handbook of Physiology. Adipose Tissue. A. E. Reynold and G. F. Cahill, editors. American Physiology Society, Washington, DC. 181-189.

34. Woolson, R. F. 1987. Statistical Methods for the Analysis of Biochemical Data. John Wiley \& Sons Inc., New York. 273 pp.

35. Ryan, N. T. 1976. Metabolic adaptations for energy production during trauma and sepsis. Surg. Clin. North Am. 56:1073-1090.

36. Wilmore, D. W. 1976. Hormonal responses and their effect on metabolism. Surg. Clin. North Am. 56:999-1018.

37. Tracey, K. J., S. F. Lowry, T. Fahey III, J. D. Albert, Y. Fong, D. Hesse, B. Beutler, K. R. Manogue, S. Calvano, H. Wei, et al. 1987. Cachectin/tumor necrosis factor induces lethal shock and stress hormone responses in the dog. Surg. Gynecol. Obstet. 164:415-422.

38. Shaw, J. H. F., and R. R. Wolfe. 1984. A conscious septic dog model with hemodynamic and metabolic responses similar to responses of humans. Surgery. 95:553-561.

39. Spector, A. A. 1975. Fatty acid binding to plasma albumin. J. Lipid. Res. 16:165-179.

40. Shaw, J. H. F., and R. R. Wolfe. 1985. Response to glucose and lipid infusions in sepsis. A kinetic analysis. Metab. Clin. Exp. 34:442-449.
41. Wolfe, R. R., and J. H. F. Shaw. 1985. Glucose and FFA kinetics in sepsis: role of glucagon and sympathetic nervous system activity. Am. J. Physiol. 248:E236-E243.

42. Van der Poll, T., J. A. Romijn, E. Endert, J. J. J. Borm, H. R. Büller, and H. P. Sauerwein. 1991. Tumor necrosis factor mimics the metabolic response to acute infection in healthy humans. Am. J. Physiol. 261:E457-E465.

43. Rofe, A. M., R. A. J. Conyers, R. Bais, J. R. Gamble, and M. A. Vadas. 1987. The effect of recombinant tumor necrosis factor (cachectin) on metabolism in isolated rat adipocyte, hepatocyte and muscle preparation. Biochem. J. 247:789-792.

44. Newsholme, E. A., and B. Crabtree. 1976. Substrate cycles in metabolic regulation and in heat regulation. Biochem. Soc. Symp. 41:61-109.

45. Wolfe, R. R., and E. J. Peters. 1987. Lipolytic response to glucose infusion in human subjects. Am. J. Physiol. 252:E218-E223.

46. Wolfe, R. R. 1989. The role of triglyceride-fatty acid cycling and glucose cycling in thermogenesis and amplification of net substrate flux in human subjects. In Hormones and Nutrition in Obesity and Cachexia. M. J. Muller, E. Danforth, Jr., A. G. Burger, and U. Siedentopp. Springer-Verlag, New York. $59-65$

47. Hellerstein, M. K., M. Christiansen, S. Kaempfer, C. Kletke, K. Wu, J. S. Reid, K. Mulligan, N. S. Hellerstein, and C. H. L. Shackleton. 1991. Measurement of de novo hepatic lipogenesis in human using stable isotopes. J. Clin. Invest. 87:1841-1852.

48. Evans, D. A., D. O. Jacobs, A. Revhaug and D. W. Wilmore. 1989. The effects of tumor necrosis factor and their selective inhibition by ibuprofen. Ann. Surg. 209:312-321.

49. Ettinger, W. H., L. D. Miller, J. J. Albers, T. K. Smith, and J. S. Parks. 1990. Lipopolysaccharide and tumor necrosis factor cause a fall in plasma concentration of lecithin: cholesterol acyltransferase in cynomolgus monkeys. $J$. Lipid. Res. 31:1099-1107.

50. Filkins, J. P., and B. J. Buchannan. 1977. In vivo vs. in vitro effects of endotoxin on gluconeogenesis and glucose utilization. Proc. Soc. Exp. Biol. Med. 155:216-218.

51. Evans, D. A., D. O. Jacobs, and D. W. Wilmore. 1989. Tumor necrosis factor enhances glucose uptake by peripheral tissues. Am. J. Physiol. 257:R1182R1189.

52. Mészáros, K., C. H. Lang, G. J. Bagby, and J. J. Spitzer. 1987. Tumor necrosis factor increases in vivo glucose utilization of macrophage-rich tissues. Biochem. Biophys. Res. Commun. 149:1-6.

53. Lee, M. D., A. Zentella, P. H. Pekala, and A. Cerami. 1987. Effect of endotoxin-induced monokines on glucose metabolism in the muscle cell line L6. Proc. Natl. Acad. Sci. USA. 84:2590-2594.

54. Bagby, G. J., C. H. Lang, D. M. Hargrove, J. J. Thompson, L. A. Wilson, and J. J. Spitzer. 1988. Glucose kinetics in rats infused with endotoxin-induced monokines or tumor necrosis factor. Circ. Shock. 24:111-121.

55. Tredget, E. E., Y. M. Yu, S. Zhong, R. Burini, S. Okusawa, J. A. Gelfand, C. A. Dinarello, V. R. Young, and J. F. Burke. 1988. Role of interleukin 1 and tumor necrosis factor on energy metabolism in rabbits. Am. J. Physiol 255:E760E768.

56. Flores, E. A., N. Istfan, J. J. Pomposelli, G. L. Blackburn, and B. R. Bistrian. 1990. Effect of interleukin-1 and tumor necrosis factor/cachectin on glucose turnover in the rat. Metab. Clin. Exp. 39:738-743.

57. Wolfe, R. R. 1982. Somatostatin infusion inhibits glucose production in burn patients. Circ. Shock. 9:521-527.

58. Revhaug, A., H. R. Michie, J. M. Manson, J. M. Watters, C. A. Dinarello, S. M. Wolff, and D. W. Wilmore. 1988. Inhibition of cyclo-oxygenase attenuates the metabolic response to endotoxin in humans. Arch. Surg. 123:162-170. 